\title{
Comments on "Cardiovascular Complications in Obstructive Sleep Apnea Syndrome”
}

\author{
Mahsa Mirdamadi ${ }^{1,{ }^{*}}$ and Ali Safaei ${ }^{1}$ \\ ${ }^{1}$ Repiratory Disease Department, Rajaie Cardiovascular Medical and Research Center, Iran University of Medical Sciences, Tehran, Iran \\ "Corresponding author: Repiratory Disease Department, Rajaie Cardiovascular Medical and Research Center, Iran University of Medical Sciences, Tehran, Iran. Email: \\ mahsa2k@yahoo.com
}

Received 2019 June 03; Accepted 2019 June 19.

Keywords: Sleep Apnea Obstruction, Cardiovascular Disease

\section{Dear Editor,}

I have read the review article entitled "Cardiovascular Complications in Obstructive Sleep Apnea Syndrome". I would like to make some contributions to this successful article and congratulate its authors.

In the review article, the authors mentioned the effect of OSA on cardiovascular system that can create both long term and acute changes in cardiovascular function like hypertension, arrhythmia, myocardial infarction, pulmonary hypertension and congestive heart failure.

Firstly, sleep apnea is a very common clinical problem and the most common type of sleep apnea is OSA. There are clinical factors leading to OSA like genetic factors, smoking, obesity, upper airway anatomic abnormalities, endocrine disturbances and drugs. Severity of OSA which can be calculated as the AHI in PSG analysis based on AASM.

Secondary, cardiovascular disease is one of the most important causes of mortality in the (1). A more developed use of evidence-based medical therapies, along with modifications in people's life style and alterations in risk factors at a population level have resulted in a decrease in heart disease mortality rates in the United States $(2,3)$.

The mechanisms involved in the cardiovascular consequences of OSA have been widely reviewed (4) OSA is associated with increased mortality and mostly increases mortality cardiovascular disease.

It is very important to distinguish OSA earlier to prevent and treat cardiovascular disease which can improve outcomes. Three large clinical trials are currently being carried out to evaluate the effects of OSA treatment on the incidence of cardiovascular diseases (Sleep Apnea Cardiovascular Endpoints (5), Randomized Intervention with CPAP in Coronary Artery Disease and Sleep Apnea (6) and
CPAP in Patients with Acute Coronary Syndrome and Obstructive Sleep Apnea (7)).

Significant evidences also point to metabolic and cardiovascular results of CPAP treatment in moderate-tosevere asymptomatic OSA patients (8). Barbe et al. (9) demonstrated no significant difference in the incidence of hypertension and cardiovascular events in a recent randomized trial of over 7 years in patients treated by CPAP compared to control groups.

After a 15-year fallow up on 6532 children and adolescents they have found a significantly higher risk of major adverse cardiovascular events (MACEs), including acute myocardial infarction, coronary artery disease, peripheral artery disease, and acute stroke, among children and adolescents (age younger than 20 years) with obstructive sleep apnea (OSA) (10).

These findings strongly suggest that clinicians should provide careful assessment and medical treatment for patient with OSA because of increased awareness about various cardiovascular complications and critical importance of their treatment.

\section{Footnotes}

Conflict of Interests: The authors of this manuscript declare no conflict of interests and received no funding or supports for this letter to editor.

Funding/Support: It is not declared by the authors.

\section{References}

1. World Health Organization. The global burden of disease: 2004 update. 2008. 
2. Ford ES, Ajani UA, Croft JB, Critchley JA, Labarthe DR, Kottke TE, et al. Explaining the decrease in U.S. deaths from coronary disease, 19802000. N Engl J Med. 2007;356(23):2388-98. doi: 10.1056/NEJMsa053935. [PubMed: 17554120].

3. Ford ES, Capewell S. Proportion of the decline in cardiovascular mortality disease due to prevention versus treatment: Public health versus clinical care. Annu Rev Public Health. 2011;32:5-22. doi: 10.1146/annurev-publhealth-031210-101211. [PubMed: 21417752].

4. Javaheri S, Barbe F, Campos-Rodriguez F, Dempsey JA, Khayat R, Javaheri S, et al. Sleep apnea: Types, mechanisms, and clinical cardiovascular consequences. J Am Coll Cardiol. 2017;69(7):841-58. doi: 10.1016/j.jacc.2016.11.069. [PubMed: 28209226]. [PubMed Central: PMC5393905].

5. McEvoy RD, Anderson CS, Antic NA, Chen B, He Q, Heeley E, et al. The sleep apnea cardiovascular endpoints (SAVE) trial: Rationale and start-up phase. J Thorac Dis. 2010;2(3):138-43. doi: 10.3978/j.issn.2072-1439.2010.02.03.5. [PubMed: 22263035]. [PubMed Central: PMC3256461].

6. Peker Y, Glantz H, Thunstrom E, Kallryd A, Herlitz J, Ejdeback J. Rationale and design of the randomized intervention with CPAP in coronary artery disease and sleep apnoea-RICCADSA trial. Scand Cardiovasc J. 2009;43(1):24-31. doi: 10.1080/14017430802276106. [PubMed:
18663661].

7. Esquinas C, Sanchez-de-la Torre M, Aldoma A, Flores M, Martinez M, Barcelo A, et al. Rationale and methodology of the impact of continuous positive airway pressure on patients with ACS and nonsleepy OSA: the ISAACC Trial. Clin Cardiol. 2013;36(9):495-501. doi 10.1002/clc.22166. [PubMed: 23843147].

8. Ryan S. Pro: Should asymptomatic patients with moderateto-severe OSA be treated? Breathe (Sheff). 2019;15(1):7-10. doi: 10.1183/20734735.0340-2018. [PubMed: 30838054]. [PubMed Central: PMC6395978].

9. Barbe F, Duran-Cantolla J, Sanchez-de-la-Torre M, Martinez-Alonso M, Carmona C, Barcelo A, et al. Effect of continuous positive airway pressure on the incidence of hypertension and cardiovascular events in nonsleepy patients with obstructive sleep apnea: A randomized controlled trial. JAMA. 2012;307(20):2161-8. doi: 10.1001/jama.2012.4366. [PubMed: 22618923].

10. Tzeng NS, Chung $\mathrm{CH}$, Chang HA, Chang CC, Lu RB, Yeh HW, et al Obstructive sleep apnea in children and adolescents and the risk of major adverse cardiovascular events: A nationwide cohort study in Taiwan. J Clin Sleep Med. 2019;15(2):275-83. doi: 10.5664/jcsm.7632. [PubMed: 30736877]. [PubMed Central: PMC6374096]. 